\title{
Kuzey Kıbrıs’ta Kadın Sağlığı ile İlgili Yapılmış Hemşirelikte Lisansüstü Tezlerin Özellikleri: Bir İçerik Analizi Çalışması
}

\section{A Content Analysis Study: Characteristics of Postgraduate Dissertations in Nursing Concerning Women's Health in North Cyprus}

\author{
Dilek Sarpkaya Güder* ve Mesut Yalvaç**
}

$\ddot{O} z$

Kuzey Kıbrıs’taki kadın sağlığının durumunu gösteren sağllk ölçütlerinde veri eksiklikleri bulunmakta ve bu durum kadın sağlı̆̆ hizmetlerinin planlanmasını olumsuz etkilemektedir. Hemşirelik alanında yapılan araştırmaların yeterli nitelikte ve nicelikte olmaması hemşireliğin bilimselleşme yolunda önemli bir sorunudur. Tüm bu sorunlar doğrultusunda, ülkedeki kadın sağlı̆̆ ile ilgili yapılmış hemşirelik araştırmalarının incelenmesi önemli görülmektedir. Bu makalenin amacı, Kuzey Kıbrıs'ta yer alan bir üniversitede kadın sağlığı ile ilgili yapılmış hemşirelikte lisansüstü tez çalışmalarını incelemektir. Araştırmanın tipi, nitel araştırma yöntemlerinden belgesel kaynak analizi ve içerik analizi yöntemidir. Araştırmanın evrenini, Kuzey Kıbrıs'ta yer alan bir üniversitenin Sağlık Bilimleri Enstitüsü Hemşirelik Programında 2010-2020 yılları arasında yapılan Ingilizce ve Türkçe lisansüstü tezler (93 tez) oluşturmuştur. Örneklem kapsamında ise kadın sağlı̆̆ı ile ilgili yapılmış 21 hemşirelikte lisansüstü tez çalışması yer almaktadır. Verilerin toplanmasında, belgeler/yayınlar yoluyla bilgi toplama tekniği kullanılmıştır. Üniversitenin kütüphane veritabanında dizinlenen tezler taranmış; veriler, araştırmacılar tarafindan oluşturulan yayın sınıflama formu aracılığı ile toplanmıştır. Bu form, araştırma stratejileri-yöntemleri, konu başlıklarl, veri toplama teknikleri, örnekleme tekniği, örgüt türü ve görsel içerik türü olmak üzere altı kategoride sinıflandırılmıştır. Çalışmada, tezlerin \%81 ile çoğunluğunun yüksek lisans tezi ve \%57,1'inin tanımlayıcı tipte araştırma olduğu, sadece 1 deneysel çalışmanın yapıldı̆̆g, \%66,7’sinde görsel içeriğin bulunduğu ve çoğunlukla kadın să̆llğını geliştirmeye yönelik çalışmaların yapıldĭ̆ı saptanmıştır. Çalışmada, tezler üzerinde veri toplama tekniği ile örnekleme teknik türü bildirimi yapılmasında hata ve eksikliklerin olduğu ve ölçek kullanımının az olduğu $(\% 33,3)$ bulunmuştur. Ülkede kadın sağlığının korunmasına, geliştirilmesine, iyileştirilmesine ve sürdürülmesine yönelik çok yönlü hemşirelik araştırmalarının artırılması, tezlerin yayına dönüşürü̈lmesi, hemşirelikte yapılan doktora tezlerinde kuram/model kullanılmasl, çalışmaların yöntem ve tekniklerinde görülen eksikliklerin gelecekte yaplacak olan çalışmalarda dikkate alınması önerilmektedir.

Anahtar Sözcükler: Araştırma; hemşirelik; içerik analizi; kadın sağlı̆̆ı.

\footnotetext{
* Yrd. Doç. Dr., Yakın Doğu Üniversitesi, Lefkoşa, Kuzey Kıbrıs. E-posta: dilek.sarpkaya@ neu.edu.tr Asist. Prof. Dr., Near East University, Nicosia, Northern Cyprus. E-mail: dilek.sarpkaya@neu.edu.tr

** Prof. Dr., Kıbrıs İlim Üniversitesi, Girne, Kuzey Kıbrıs. E-posta: yalvacmesut@ hotmail.com

Prof.Dr., Cyprus Science University, Kyrenia.E-mail:yalvacmesut@hotmail.com
}

Geliş Tarihi - Received: 04.11.2020

Kabul Tarihi - Accepted: 22.02.2021 


\section{Abstract}

There are health criterion data gaps indicating the status of women's health in North Cyprus and therefore, this situation affects adversely the planning of women's health services. Insufficient quality and quantity of research studies in the field of nursing is a significant problem in the way of scientification of nursing. Considering all of these problems, it is deemed important to examine nursing research studies conducted on women's health in the country. The aim of this article is to investigate the postgraduate dissertation studies conducted regarding the women's health at one of the universities in North Cyprus in Nursing. The research has been conducted by using document analysis and content analysis tools, which are included in the qualitative research methods. The universe of this research consists of postgraduate dissertations in English and Turkish languages (93 theses) written between 2010 and 2020 in the Institute of Health Sciences, Nursing Program, at a university in North Cyprus. The sample of this research also consists of 21 postgraduate dissertation studies concerning women's health. Data collection technique through documents/publications has been used in the data collection process. Dissertations indexed in databases of library of the university have been scanned and the data has been collected by the way of publication classification form generated by researchers. This form has been classified into six categories: research strategies/methods, topic titles, data collection techniques, sampling technique, organization type, and visual content type. It has been determined in the study that the majority of the dissertations are master's theses with $81 \%, 57.1 \%$ of them are descriptive studies, only one experimental study was done, and $66.7 \%$ of them have the visual content. It has also been ascertained that most of the studies have been written regarding the improvement of women's health. In the study, it has been found out that there are errors and deficiencies in data collection technique and sampling technique type statements on dissertations. Also, the use of scale has been found to be insufficient with the percentage of $33.3 \%$. It is recommended to increase the number of multifaceted Nursing research devoted to the protection, development, improvement and maintenance of women's health in the country, to convert these studies into publications, to use theories/models in doctoral dissertations in Nursing, and to consider the deficiencies observed in the methods and techniques of the studies for future studies.

Keywords: Research; nursing; content analysis; women's health.

\section{Giriş}

Hemşirelik mesleğinde yapılan araştırmalar, hemşirelik uygulamaları için güçlü bir bilimsel taban ve kanıta dayalı uygulamalara sağlam bir temel oluşturabilmektedir (Aksayan, Bahar ve Bayık, 2004; Karabulut, Gürçayır ve Aktaş, 2019). Kanıta dayalı uygulama, düzenli ve kurallara uygun olarak yapılmış araştırma sonuçlarının hasta bakımında kullanılması olarak tanımlanmaktadır. Bu bağlamda hemşirelik araştırmalarının kanıta dayandırılması, bakım kalitesinin yükseltilmesi açısından son derece önemlidir (Aksayan, Bahar ve Bayık, 2004). Günümüzde hemşirelik bilimi alanında önemli klinik bilgileri ele alan ve hemşirelik bilgi tabanına katkı sunan araştırmaların yapılmasına ihtiyaç duyulmaktadır. Ayrıca hemşirelik alanında yapılan deneysel araştırmalara gereksinim de giderek artmaktadır. Hemşirelikte daha çok tanımlayıcı araştırmaların yapılması ve kuram ile modellerin çok az kullanılması hemşireliğin bilimselleşme yolunda önemli sorunlarıdır. Tüm bunlar doğrultusunda hemşirelik 
Kuzey Kıbrıs’ta Kadın Sağlığı ile İlgili Yapılmış Hemşirelikte Lisansüstü Tezlerin Özellikleri: Bir İçerik Analizi Çalışması

A Content Analysis Study: Characteristics of Postgraduate Dissertations in Nursing Concerning Women's Health in North Cyprus

araştırmalarına yön verecek olan Türkiye ve Kuzey Kıbrıs’ta hemşirelikte yapılan araştırmaları inceleyen içerik analizi çalışmaları çok yetersizdir (Ardahan ve Özsoy, 2015; Dağcı, 2019; Emiroğlu, Kuru ve Çopur, 2018; Karabulut, Gürçayır ve Aktaş, 2019; Paşalak, Eroğlu ve Akyüz, 2018).

Kuzey Kıbrıs'ta nüfusun \%47,4'ünü kadınlar oluşturmakta ve kadın sağlı̆̆ının durumunu gösteren sağlık ölçütlerinde veri eksiklikleri bulunmaktadır (Devlet Planlama Örgütü, 2017). Ayrıca ülkede kadın sağlığı ile ilgili yapılmışşalışmalar sınırlıdır. Kadın sağlığı ile ilgili yapılmış çalışmalar incelendiğinde; üç adet cinsel yolla bulaşan enfeksiyon (Akalpler ve Eroğlu, 2015; Kaptanoğlu, Süer, Diktaş ve Hinçal, 2013; Süer, Güvenir, Güler ve Diktaş, 2012), beş adet kadına yönelik şiddet (Çakıcı, Çakıcı, Bayraktar, Subaşı, Karademir, Kayagül ve Atabey, 2001; Çakıcı, Düşünmez ve Çakıcı, 2007; Mammadov, Vural ve Tosun, 2018; Masaroğulları ve Uzunboylu, 2017; Mertan, Bayraktar, Pehlivan, Maner, Hüsnü ve Çelik, 2012), üç adet kadına yönelik kanser (Hinçal, Taneri, Taneri ve Djamgoz, 2008; Pervaiz, Tulay, Faisal ve Serakinci, 2017; Sancar, Nalca Andrieu, Hincal ve Granit, 2017), iki adet aile planlaması yöntemleri ile kürtaj (Asit, 2019; Sarpkaya ve Eroğlu, 2011), üç adet emzirme (Özlüses ve Çelebioglu, 2014; Sökücü Yorgancı ve Aslan, 2012; Şafak ve Tutkun, 2015) ve dört adet doğum ve doğum sonrası dönem (Akalpler ve Okumus, 2018; Mammadov, Vural, Aytac ve Mammadov, 2019; Sarpkaya Güder, Yalvaç ve Vural, 2018; Sarpkaya Güder, Yalvaç ve Vural, 2019) ile ilgili araştırmalara rastlanmıştır. Kadın sağlığı ile ilgili çalışmaların belirlenmesi, kadın sağlığı açısından koruyucu ve tedavi edici hizmetlerin geliştirilmesi açısından büyük önem taşımaktadır. Bu doğrultuda kadın sağlığına ilişkin yapılan tez çalışmalarının hangi konularda yapıldığının incelenmesi, yeni planlanacak olan çalışmalara yol gösterebilmesi bakımdan anlamlı görülmektedir.

Kuzey Kıbrıs'ta günümüzde yedi üniversitede hemşirelikte lisans eğitimi verilmektedir. Bu üniversitelerin beşinde yüksek lisans ve ikisinde doktora eğitimi olmak üzere lisansüstü eğitimler yürütülmektedir. Hemşirelikte lisansüstü eğitim ilk kez 2007 yılında Yakın Doğu Üniversitesi'nde verilmeye başlanmıştır. Üniversitenin Sağlık Bilimleri Enstitüsüne bağlı Hemşirelik Programı'nda, 2007 yılından itibaren yüksek lisans, 2008 yılından itibaren ise doktora programları devam etmektedir. Bu programların içerisinde Kadın Sağlı̆̆ı ve Doğum, Çocuk Sağlığı ve Hastalıkları ile Halk Sağlığı Hemşireliği Anabilim Dallarında kadının sağlık durumuna ilişkin araştırmalar yapılabilmektedir. Bu alanlarda ne sıklıkla ve kadın sağlı̆̆ına ilişkin hangi konularda araştırmaların yapıldığının belirlenmesi, bunun yanı sıra araştırmalarda kullanılan yöntem ve tekniklerin neler olduğunun saptanması, bu alandaki çalı̧̧maların niteliğinin ve niceliğinin değerlendirilmesinde ve gelecekteki çalışmaların planlanmasında önem taşımaktadır. Bu doğrultuda, eksik olan boşlukların yeni planlanacak olan çalışmalara yol gösterebilmesi bakımından çalışma anlamlı görülmektedir. Çalışmada elde edilen verilerin, hemşirelik araştırmalarına yön vereceği, hazırlanan tezlerin yayın aşaması sürecinde makalelerin geliştirilmesine de önemli katkılar sağlayacağı düşünülmektedir.

Türkiye'de hemşirelik alanında kadın sağlığına ilişkin tez çalışmalarını inceleyen bir içerik analizi çalışmasında; 2012-2017 yılları arasında cinsel sağlık ve üreme sağlı̆̆ konularında yapılmış olan tezlerin çoğunluğunun tanımlayıcı türde olduğu, \%53,3'ünde 
örnekleme yöntemi kullanıldığı ve cinsellik konularında çok fazla çalışma yapılmadığ belirlenmiştir (Yüksel Koçak ve Büyükkayacı Duman, 2019). Kuzey Kıbrıs'ta hemşirelik alanında kadın sağlığı ile ilgili içerik analizi çalışmalarına rastlanmamıştır. Makalenin amacı, Kuzey Kıbrıs'ta yer alan bir üniversitede kadın sağlığı ile ilgili yapılmış hemşirelikte lisansüstü tez çalışmalarını, belgesel kaynak analizi ve içerik analizi yöntemleriyle incelemektir. Bu amaç doğrultusunda aşağıda yer alan sorulara yanıt aranmıştır:

- Kadın sağlığı ile ilgili hemşirelikte yapılmış lisansüstü tezlerin genel özellikleri (konu alanı, tez türü, araştırma tipi, örgüt türü ve görsel içerik türü) nelerdir?

- Kadın sağlığg ile ilgili hemşirelikte yapılmış lisansüstü tezlerin araştırma yöntem ve teknikleri nelerdir?

\section{Yöntem}

Araştırma Türü: Araştırmanın tipi, nitel araştırma yöntemlerinden belgesel kaynak analizi ve içerik analizi yöntemidir. Belgesel kaynak analizinde temel amaç, araştırılması hedeflenen olgu veya olaylar üzerinde bilgi, düşünce ve insan yaratması taşıyan her türden kaynağın (yazıl1, basılı, çizili, görsel, işitsel vd.) saptanması, elde edilmesi, doğruluk, güvenilirlik, gerçeklik, geçerlilik ve güncellik açılarından nitelik kalitelerini de gözeterek sistemli olarak analizini yapmaktır (Best, 1959; Bogdan ve Biklen, 1982; Duverger, 1973; Yıldırım ve Şimşek, 2006). Belgesel kaynak analizi, hemen her araştırma için kullanılması kaçınılmaz olan bir araştırma yöntemidir (Madge, 1965). İçerik analizi yöntemi, toplanan verileri açıklayabilecek kavramlara ve ilişkilere ulaşmayı amaçlamaktadır. Betimsel analiz yönteminde özetlenen ve yorumlanan veriler, içerik analizi yöntemine göre daha derin bir işleme tabi tutulmaktadır. İçerik analiz yönteminde temelde yapılan işlem, birbirine benzeyen verileri belirli kavramlar ve temalar çerçevesinde bir araya getirmek ve bunları okuyucunun anlayabileceği bir biçimde organize ederek yorumlamaktır (Yıldırım ve Şimşek, 2006). Ayrıca içerik analiz yöntemi, belirli kurallara dayalı kodlamalarla yapılan niceliksel ve elde bulunan kayıtlı metinlerin çözümlenmesine yönelik bir yöntem olarak tanımlanmaktadır (Yıldırım, 2015).

Evren ve Örneklem: Kuzey Kıbrıs'ta Yakın Doğu Üniversitesi'nin Sağlık Bilimleri Enstitüsü Hemşirelik Programı'nda 2010-2020 yılları arasında yapılan İngilizce ve Türkçe lisansüstü tezler (93 tez) çalışmanın evrenini oluşturmuştur. Hemşirelikte lisansüstü eğitiminin ilk başladığı üniversite olmasının yanı sıra hemşirelikte hem yüksek lisans hem de doktora eğitiminin ve öğretiminin verildiği tek üniversite olması ve diğer üniversitelerin tezlerine açık erişim olmaması nedeniyle bu üniversite seçilmiştir. Kadın sağlığına ilişkin yapılan 21 hemşirelikte lisansüstü tez çalışması, çalışmanın örneklemini oluşturmaktadır.

Veri Toplama: Verilerin toplanmasında belgeler/yayınlar yoluyla bilgi toplama tekniği kullanılmıştır. 16 Mart 2020 tarihinde üniversitenin Büyük Kütüphane veritabanında dizinlenen Sağlık Bilimleri Enstitüsü Hemşirelik Programı'nda yapılmış yüksek lisans ve doktora tezleri taranmıştır. Bu tez çalışmaları web adresinden (NEU Grand Library, 2020) tez açıklamasında 'Hemşirelik', 'Yüksek Lisans', 'Doktora' ve 'Tez' kavramları geçen araştırmalar Türkçe ve İngilizce olarak taranarak elde edilmiştir. Tarama sonucunda 10'u İngilizce, 78'i Türkçe olmak üzere 88 adet yüksek lisans ve 5 adet Türkçe doktora tezine ulaşılmıştır. İçerik analizine tabi tutulmak üzere 3'ü İngilizce olmak üzere kadın sağlığına ilişkin 21 adet çalışma incelenmiştir. Bu çalışmalara ulaşmak için lisansüstü tezlerin anahtar 
Kuzey Kıbrıs’ta Kadın Sağlığı ile İlgili Yapılmış Hemşirelikte Lisansüstü Tezlerin Özellikleri: Bir İçerik Analizi Çalışması

A Content Analysis Study: Characteristics of Postgraduate Dissertations in Nursing Concerning Women's Health in North Cyprus

kelime arama butonundan 'kadın', 'kadın sağlığı', 'anne', 'gebelik', 'doğum', 'hamilelik' ve 'kadın hastalıkları' kavramları taratılmıştır. Ayrıca tezlerin başlıkları ile tarama yapılıp, tez başlıklarına göre kadın sağlığıyla ilgili çalışma olup olmadığı kontrol edilmiştir. Veriler, araştırmacılar tarafından oluşturulan yayın sınıflama formu aracılığı ile toplanmıştır. Bu form, araştırma stratejileri-yöntemleri, konu başlıkları, veri toplama teknikleri, örnekleme tekniği, örgüt türü ve görsel içerik türü olmak üzere altı kategoride sınıflandırılmıştır. Konu başlıkları, Kadın Sağlığı ve Doğum, Çocuk Sağlığı ve Hastalıkları ile Halk Sağlığı Hemşireliği anabilim dallarının kadın sağlığıyla ilgili ele aldıkları ana konular göz önünde bulundurularak oluşturulmuştur.

Veri Analizi: Elde edilen veriler, SPSS 20 paket programı kullanılarak analiz edilmiştir. Çalışmanın verileri; kavramsal, betimlenebilir nitelikte ve sayısal olarak belirtilmiştir. Araştırmada yer alan tezlere ilişkin verilerin çözümlenmesinde sayı, yüzde, ortalama hesaplamalarından yararlanılmış ve veriler tablo ve grafik kullanılarak sunulmuştur.

\section{Bulgular}

Araştırma kapsamında incelenen çalışmaların 2010-2020 yılları arasında yapıldığı, \%81 ile çoğunluğunun yüksek lisans tezi olduğu, tezlerin \%85,7'sinin Türkçe metin dili ile yazıldiğ ve tamamının tek danışman tarafından yürütüldüğ̈̈ saptanmıştır. Tezlerde kaynak kullanım sayısı 50-235 arasında değişmektedir.

Araştırma kapsamına alınan tezlerin \%66,7'sinde görsel içerik kullanıldığı, kullanılan görsel içeriklerin en fazla sirasıyla grafik (10 tez), şekil ( 8 tez) ve fotoğraf ( 8 tez) olduğu saptanmıştır. Çalışmaların \%33,3'ünde ölçek kullanıldığı ve bu ölçeklerin üçünün 5'li, ikisinin 4'lü, birinin 6'lı ve birinin hem 3'lü hem de 4'lü likert tipte ölçek olduğu saptanmıştır. Çalışma kapsamına alınan lisansüstü tez çalışmalarının yıllara göre dağılımı Grafik 1'de gösterilmektedir. Grafik 1'de görüldüğü gibi 2012-2014 yılları arasında ve 2017 yılında, kadın sağ lığı alanında çalışma yapılmamış olup, 2010 yılından 2020 yılına kadar da alana ilişkin yapılan tezlerde düşüş yaşanmıştır.

\section{Grafik 1}

Lisansüstü Tez Çalışmalarının Yıllara Göre Dağılımı (n=21)

TEZ SAYISI

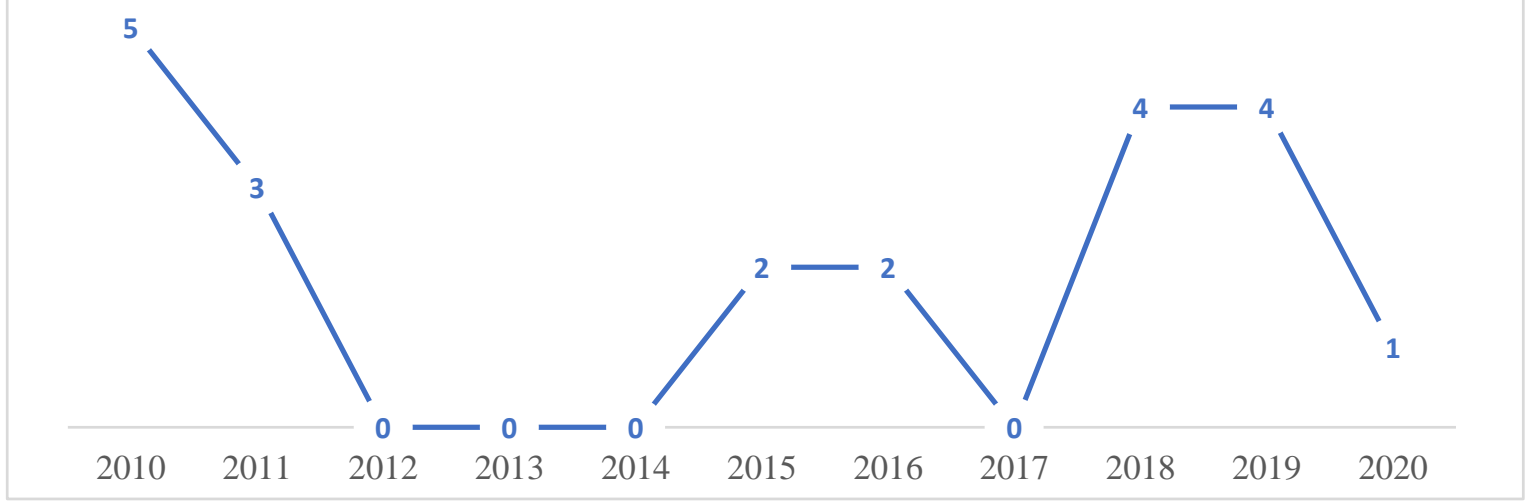




\section{Tablo 1}

Tezlerin ilgili olduğu hemşirelikte temel alanlar ve kadın să̆llğı ile ilgili ana konuların dağılımı $(n=21)$

\begin{tabular}{lll}
\hline Temel Alanlar & Sayı (n) & Yüzde (\%) \\
\hline Kadın sağlığı ve doğum hemşireliği & 20 & 95,2 \\
Halk sağlığı hemşireliği & 8 & 38,0 \\
Çocuk sağlığı ve hastalıkları hemşireliği & 1 & 4,7 \\
\hline Ana Konular & Sayı (n)* & Yüzde (\%) \\
\hline Kadın sağlı̆̆ının geliştirilmesi & 4 & 19,0 \\
Yenidoğanın fizyolojisi, bakımı, beslenmesi & 3 & 14,3 \\
Aile planlaması ve gebeliğin önlenmesi & 2 & 9,5 \\
Cinsel yolla bulaşan enfeksiyonlar & 2 & 9,5 \\
Doğum sonu dönem ve bakım & 2 & 9,5 \\
Kadın hayatının devreleri & 2 & 9,5 \\
Gebeliğin psikososyal ve kültürel boyutları & 2 & 9,5 \\
Jinekolojik kanserler & 1 & 4,8 \\
Ebeveynliğe hazırlanma ve doğum öncesi bakım & 1 & 4,8 \\
Meme neoplazileri & 1 & 4,8 \\
Cinsel sağlık ve üreme sağlığı & 1 & 4,8 \\
Anne çocuk sağlığı & 1 & 4,8 \\
Kadına yönelik şiddet & 1 & 4,8
\end{tabular}

* Birden fazla seçenek olduğundan yüzdeler $\mathrm{n}$ değerine göre alınmıştır.

Tablo 1'de çalışma kapsamına alınan tezlerin ilgili olduğu hemşirelik programının alanlarında yer alan kadın sağlı̆̆ ile ilgili ana konuların dağılımı bulunmaktadır. Tezler, en fazla kadın sağlı̆̆ ve doğum hemşireliği alanlarında hazırlanmıştır. Kadın sağlı̆̆ına ilişkin yapılan tezlerin ana konusunun en fazla, kadın sağlığının geliştirilmesine yönelik olduğu ve en az jinekolojik kanserler ve meme neoplazileri, ebeveynliğe hazırlanma ve doğum öncesi bakım, anne çocuk sağlı̆̆ı, üreme ve cinsel sağlık ile kadına yönelik şiddet konularında olduğu görülmektedir.

\section{Tablo 2}

Tezlerin kullandığı araştırma strateji ve yöntemlerinin dağılımı $(n=21)$

\begin{tabular}{lll}
\hline Strateji/Yöntem Bildirimi & Sayı (n) & Yüzde (\%) \\
\hline Var & 21 & 100,0 \\
Yok & 0 & 0,0 \\
\hline Strateji/Yöntemler & & \\
\hline Betimleyici/tanımlayıcı & 13 & 57,1 \\
Yarı deneysel & 3 & 14,3 \\
Deneysel & 1 & 4,8 \\
Geçersiz* & 4 & 19,0 \\
\hline
\end{tabular}

*Hatalı bildirim yapıldığı için geçersiz kabul edilmiştir.

Çalışma kapsamına alınan tezlerin kullandığı araştırma strateji ve yöntemlerinin dağılımı Tablo 2'de yer almaktadır. Çalışmaların tamamında araştırma yöntemi belirtilmiştir. Çalışmaların \%57,1'inin betimleyici/tanımlayıcı tipte araştırma olduğu ve yalnızca bir deneysel çalışmanın yapıldığı bulunmuştur. 
Kuzey Kıbrıs’ta Kadın Sağlığı ile İlgili Yapılmış Hemşirelikte Lisansüstü Tezlerin Özellikleri: Bir İçerik Analizi Çalışması

A Content Analysis Study: Characteristics of Postgraduate Dissertations in Nursing Concerning Women's Health in North Cyprus

Tablo 3

Tezlerin örnekleme tekniği bildirim durumu ve kullandiğı tekniklere göre dă̆ıllımı $(n=21)$

\begin{tabular}{lll}
\hline Örnekleme Teknik Türü Bildirimi & Sayı (n) & Yüzde (\%) \\
\hline Yok & 16 & 76,2 \\
Var & 5 & 23,8 \\
\hline Örneklem Seçim Tekniği (n=5) & & \\
\hline Olasılıklı örnekleme tekniği & 3 & 60,0 \\
Olasılıksı örnekleme tekniği & 2 & 40,0 \\
\hline Olasılıklı Örnekleme Teknikleri* & \\
\hline Tabakalı Rastgele Örnekleme & 6 & 28,5 \\
Basit Rasgele Örnekleme & 5 & 23,8 \\
Küme Örnekleme & 2 & 9,5 \\
Geçersiz $^{* *}$ & 12 & 57,1 \\
\hline
\end{tabular}

* Birden fazla seçenek olduğundan yüzdeler $\mathrm{n}$ değerine göre alınmıştır.

*** Teknik bildirimi açıklanmadığı için geçersiz kabul edilmiştir.

Tablo 3'te tezlerin örnekleme tekniği bildirim durumu ve kullandığg tekniklere göre dağılımı belirtilmiştir. Tezlerin evren ve örneklem bildirim durumları incelendiğinde, tamamının evren bildirimini yaptığı ve \%76,2'sinin örnekleme teknik bildirimi yapmadığ 1 saptanmıştır. Olasılıklı örnekleme tekniği bildirimi yapılmış tezlerin \%57,1'inde olasılıklı örnekleme tekniği türü bildirimi yapılmadığı veya hatalı yapıldığı için geçersiz kabul edilmiştir. Olasılıklı örnekleme seçim tekniğini bildiren çalışmalarda, en fazla \% $\% 28,5$ ile tabakalı rastgele örnekleme tekniği kullanıldığı belirlenmiştir.

\section{Tablo 4}

Tezlerin kullandiğı veri toplama tekniklerine göre dağılımı $(n=21)$

\begin{tabular}{lll}
\hline Teknik Türü Bildirimi & Sayı (n) & Yüzde (\%) \\
\hline Var & 21 & 100,0 \\
Yok & 0 & 0,0 \\
\hline Veri Toplama Teknikleri* & \\
\hline Anket & 19 & 90,4 \\
Görüşme (teke tek görüş̧me) & 12 & 57,1 \\
Gözlem & 3 & 14,3 \\
Belgeler yayınlar yoluyla (kayıl analizi) & 1 & 4,8 \\
Deney ya da laboratuvar uygulamalarında & 1 & 4,8 \\
Geçersiz** $^{*}$ & 8 & 38,0 \\
\hline
\end{tabular}

*Birden fazla seçenek olduğundan yüzdeler $\mathrm{n}$ değerine göre alınmıştır.

*** Bildirim yapılmadığ 1 veya hatalı bildirildiği için geçersiz kabul edilmiştir.

Tablo 4'te çalışma kapsamına alınan tezlerin kullandığı veri toplama tekniklerine göre dağılımı verilmiştir. Çalışmaların tamamında veri toplama tekniği bildirimi yapılmasına karşın, \%38'inde uygun bir veri toplama teknik türü belirtilmediği veya hatalı bildirim yapıldığı için geçersiz olarak kabul edilmiştir. Veri toplama tekniği bildiren tezlerde en fazla anket ile teke tek görüşme tekniğinin kullanıldığı ve deney ya da laboratuvar uygulamaları ile belgeler yayınlar yoluyla veri toplama tekniği kullanan az çalışma olduğu belirlenmiştir. 


\section{Grafik 2}

Tezlerin örgüt türlerine göre dağılımı $(n=21)$

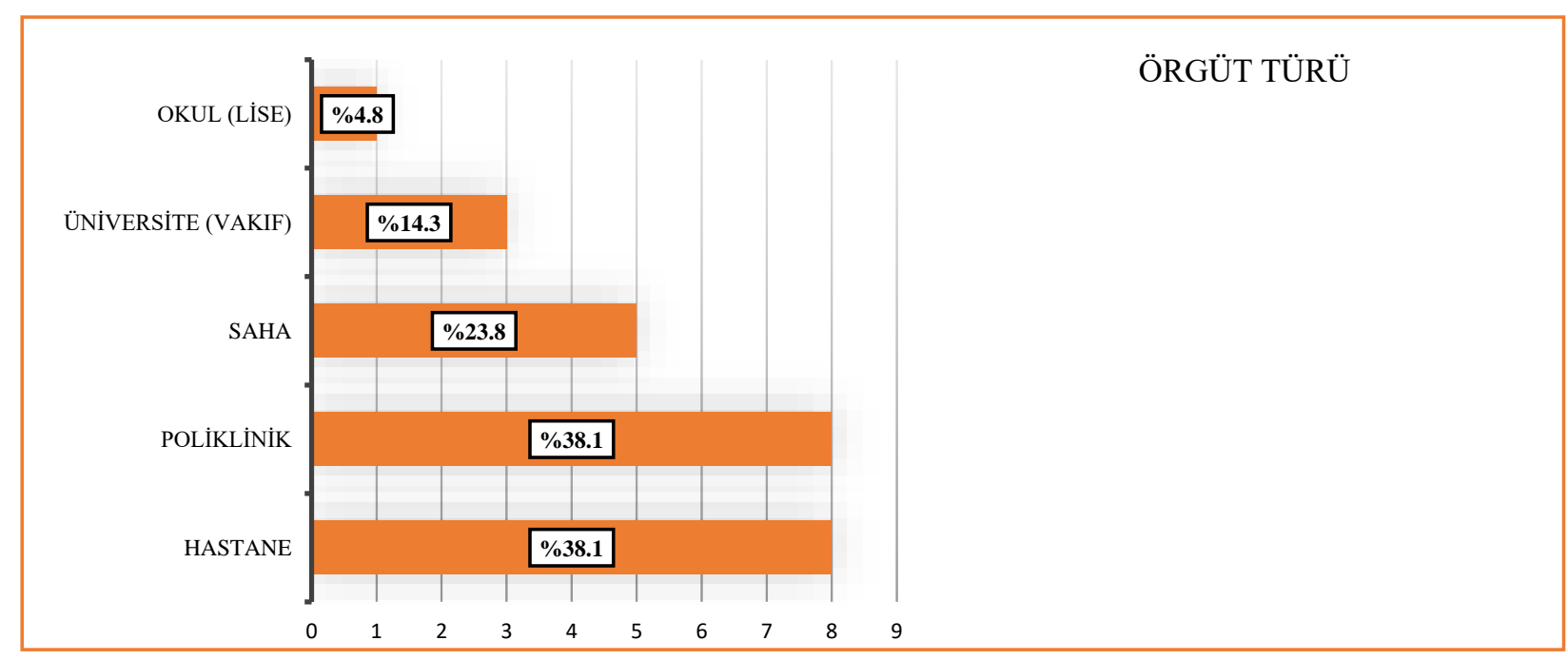

Tezlerin örgüt türlerine göre dağılımı Grafik 2'de gösterilmektedir. Tezlerin örgüt türleri incelendiğinde, çalışmaların en fazla hastanelerde $(\% 38,1)$, polikliniklerde $(\% 38,1)$ ve sahada $(\% 23,8)$ yapıldığı bulunmuştur. Çalışmada birden fazla örgüt türü kullanan araştırmalar bulunmaktadır. Hastane ve polikliniklere; üniversite, eğitim ve araştırma, özel ve kamuya ait hastane ve poliklinikler, üniversitelere; vakıf ve devlete ait üniversiteler dahil edilmiştir.

\section{Tartışma}

Bu çalışma, Kuzey Kıbrıs'ta hemşirelikte lisansüstü eğitimin ilk olarak verilmeye başlandığı (2007'de) özel bir üniversitede, kadın sağlığı ile ilgili yapılmış hemşirelikte lisansüstü tez çalışmalarını içerik analizi yöntemiyle incelemek amacıyla hazırlanmıştır. Türkiye'de hemşirelik alanıyla ilgili yapılmış tezlerin bir içerik analizi çalışmasında, en az cinsellik konularına ilişkin çalışmaların yapıldığı saptanmıştır. Bu çalışmada, hemşirelikte kadın sağlığı ile ilgili yapılmış tez çalışmalarının ana konularının; en az jinekolojik kanser ve meme neoplazileri, doğum öncesi bakım, anne çocuk sağlı̆̆ı, üreme ve cinsel sağlık ile kadına yönelik şiddet konularında olduğu belirlenmiş ve cinsellikle ilgili çalışmalara rastlanmamıştır (Tablo 1). Kadın sağlığının geliştirilmesinde koruyucu hizmetler ile ilgili yapılmış araştırmalar önemli olmakla birlikte, tedavi edici hemşirelik bakım hizmetlerinin geliştirilmesine ilişkin araştırmaların yapılmasına da gereksinim duyulmaktadır.

Kuzey Kıbrıs’taki kadın sağlığının durumunu gösteren sağlık ölçütlerinde veri eksiklikleri bulunmaktadır. Bundan dolayı ülkedeki kadın sağlığına ilişkin yapılan gerek tez gerekse bilimsel yayınlar, ülkedeki kadının sağlık durumu hakkında bilgi verebilmesi bakımından önemli görülmektedir. Ülkedeki hemşirelikte lisansüstü tezler dışında kadın sağlığı ile ilgili yapılmış çalışmalar incelendiğinde; en fazla kadına yönelik şiddet konusunda (Çakıcı, Çakıcı, Bayraktar, Subaşı, Karademir, Kayagül ve Atabey, 2001; Çakıcı, Düşünmez ve Çakıc1, 2007; Mammadov, Vural ve Tosun, 2018; Masaroğulları ve Uzunboylu, 2017; Mertan, Bayraktar, Pehlivan, Maner, Hüsnü ve Çelik, 2012), en az da aile planlamas1 yöntemleri ve kürtaj ile ilgili konularda çalışma yapıldığı (Asit, 2019; Sarpkaya ve Eroğlu, 2011) görülmektedir. Yapılmış çalışmaların (Akalpler ve Eroğlu, 2015; Akalpler ve Okumus, 
Kuzey Kıbrıs’ta Kadın Sağlığı ile İlgili Yapılmış Hemşirelikte Lisansüstü Tezlerin Özellikleri: Bir İçerik Analizi Çalışması

A Content Analysis Study: Characteristics of Postgraduate Dissertations in Nursing Concerning Women's Health in North Cyprus

2018; Asit, 2019; Çakıcı, Çakıcı, Bayraktar, Subaşı, Karademir, Kayagül ve Atabey, 2001; Çakıcı, Düşünmez ve Çakıcı, 2007; Hinçal, Taneri, Taneri ve Djamgoz, 2008; Kaptanoğlu, Süer, Diktaş ve Hinçal, 2013; Mammadov, Vural, Aytac ve Mammadov, 2019; Mammadov, Vural ve Tosun, 2018; Masaroğulları ve Uzunboylu, 2017; Mertan, Bayraktar, Pehlivan, Maner, Hüsnü ve Çelik, 2012; Özlüses ve Çelebioglu, 2014; Pervaiz, Tulay, Faisal ve Serakinci, 2017; Sancar, Nalca Andrieu, Hincal ve Granit, 2017; Sarpkaya ve Eroğlu, 2011; Sarpkaya Güder, Yalvaç ve Vural, 2018; Sarpkaya Güder, Yalvaç ve Vural, 2019; Sökücü Yorgancı ve Aslan, 2012; Süer, Güvenir, Güler ve Diktaş, 2012; Şafak ve Tutkun, 2015) ana konuları incelendiğinde gerçekleştirilen bu çalışmayla benzer şekilde, jinekolojik hastalıklar ve bakım, gebelik, doğum öncesi bakım konularında daha az çalışma yapıldığı görülmektedir. Literatürde ulaşılan bu çalışmaların içinde, araştırma kapsamında ele alınan lisansüstü tezler ile karşılaş̧ırıldığında tezlerin 4'ü doktora olmak üzere sadece 7'sinin yayına dönüştürüldüğü görülmektedir. Tezlerin ve araştırmaların bilim dünyasına katkısı, sonuçlarının paylaşılmasına bağlıdır. Bu nedenle yayınlanmamış tezlerin yayına dönüşmemesi nedenlerinin araştırılması, tezlerin tamamının yayına dönüşmesinin desteklenmesi ve yayınların ulaşılabilirliğinin artırılması gerekmektedir (Emiroğlu, Kuru ve Çopur, 2018).

Hemşirelikte deneysel araştırmalara gereksinim duyulmaktadır. Çalışmada, tezlerin $\% 57,1$ 'inin betimleyici/tanımlayıcı tipte araştırma olduğu bulunmuştur (Tablo 2). Bu durumun nedeni, çoğunun (\%81) yüksek lisans tezi olması, deneysel araştırmaların ise daha çok doktora düzeyinde beklenilmesinden kaynaklı olabilir. Deneysel çalışmaların yanı sıra nitel araştırma yöntemi de hemşirelik araştırmaları için önemlidir. Türkiye'de hemşirelik alanında nitel araştırma yöntemleri 2002 yılından itibaren artış göstermektedir (Durmuş, 2016). Bu çalışmada, kadın sağlığı ile ilgili yapılan hemşirelikte tez çalışmalarında nitel araştırma yöntemine rastlanmamıştır. Türkiye'de 2009-2016 yılları arasında hemşirelikte iş sağlığı alanında yapılan lisansüstü tezlerin değerlendirildiği bir çalışmada (Emiroğlu, Kuru ve Çopur, 2018); yürütülen tezlerin çoğunda $(\% 84,6)$ tanımlayıc1 araştırma deseninin kullanıldığ bulunmuş olup, hazırlanan tezlerin büyük çoğunluğu $(\% 86,7 ; n=13)$ yayınlanmamıştır. Ardahan ve Özsoy'un (2015) 1984-2007 yıllarına ait Yükseköğretim Kurumu arşivinde kayıtlı olan hemşirelik tez adlarının incelendiği araştırmasında, en fazla tanımlayıcı araştırmaların yapıldığı, Yüksel Koçak ve Büyükkayacı Duman'ın (2019) çalışmasında ise, 2012-2017 yılları arasında cinsel sağlık ve üreme sağ lığı konularında yapılmış olan tezlerin çoğunluğunun tanımlayıcı türde olduğu ve nitel hiçbir çalışmaya rastlanmadığı belirlenmiştir. Bu çalışma sonuçları, yapılan çalı̧̧ma sonucunu destekler niteliktedir.

Yurtdışında 2000-2004 yılları arasında yapılmış hemşirelikte doktora tez çalışmalarını inceleyen sistematik derleme çalışmasında, tezlerin \%27'sinde hemşirelik kuram/modellerinin kullanıldığı saptanmıştır (Spear, 2007). Paşalak, Eroğlu ve Akyüz (2018) çalışmasında; 19892017 yılları arasında Yükseköğretim Kurumu Ulusal Tez Merkezi veritabanı, kadın sağlığı hemşireliği alanında en fazla kuram ve modellerin kullanıldığı obstetri/kadın doğum alanında, 15 lisansüstü tez çalışmasının olduğu saptanmıştır. Bu çalışma kapsamına alınan hemşirelikte lisansüstü tezler içerisinde yer alan doktora çalışmalarında kuram/model kullanılmadığı dikkati çekmektedir. 
Çalışma kapsamına alınan tezlerin örneklem bildirim durumları incelendiğinde, \%76,2'sinde örnekleme teknik bildirimi yapılmadığı belirlenmiştir. Olasılıklı ve olasılıksız örneklem tekniği bildirimi yapılmaması eksiklik olarak görülmüştür. Çalışmada olasılıklı örnekleme seçim tekniğini bildiren çalışmalarda, en fazla \%28,5 ile tabakalı rastgele örnekleme tekniği kullanıldığı belirlenmiştir. Türkiye'de 2012-2017 yılları arasında cinsel sağlık ve üreme sağlı̆̆ konularında yapılmış olan 12 tezin \%46,7'sinde örneklem hesabına gidilmediği saptanmıştır (Yüksel Koçak ve Büyükkayacı Duman, 2019). Bu sonuç, yapılan bu çalışmanın sonucunu da destekler nitelikte olup, olasılıksız örnekleme tekniklerinin daha fazla kullanıldığgnı düşündürmektedir.

Çalışma kapsamına alınan tezlerin çoğunda anket yöntemi ve görüşme yönteminin fazla kullanıldığı, gözlem yönteminin az kullanıldığı saptanmıştır. Çalışmalarda ölçek kullanımının az $(\% 33,3)$ olduğu ve tezlerin \%40'1nda veri toplama tekniğinin hatalı veya bildirim yapılmadan aktarıldığı belirlenmiştir. Yalvaç'a (2000) göre anket, belli bir amaçla işletme sistemine ilişkin çeşitli soruları ve bilgi isteklerini içeren önceden hazırlanmış 'anket formları' ile bilgi toplama tekniği olarak tanımlanmaktadır ve bu teknikte kişilerden anket formlarını kendilerinin doldurmaları/yanıtlamaları istenir. Görüşme yönteminde ise, doğrudan doğruya kişiler ile özel 'teke tek görüşmeler' yapılarak veriler toplanmaktadır. Çalışma kapsamında incelenen tezlerde görüşme tekniği bildirilen çalışmalarda aslında teke tek görüşme tekniği yerine anket yolu ile verilerin toplandığı görülmektedir. Bu nedenle veri toplama tekniği bildiriminde hata olduğu düşünülmektedir. Bunun yanı sıra anket tekniği ve bilgi toplama sırasında, anket formlarını yanlış ve eksik anlama, eksik yanıtlama, yanlış bilgi verme vb. gibi sorunların sıklıkla yaşanabilmesinden dolayı karşılaşılabilecek sorunları en aza indirmek için gerekli önlemlerin alınıp alınmamasının araştırmalarda belirtilmesi gerektiği de düşünülmektedir.

Çalışma kapsamında incelenen tezlerin \%23,8'inin sahada yapıldığı bulunmuş olup, kadın sağlığını geliştirmeye yönelik yapılacak olan çalışmaların sahada daha çok yapılması gerektiği düşünülmektedir. Her bilim ve uygulama alanında olduğu gibi hemşirelik bilim ve uygulama alanında da teori ile uygulama ilişkisinin ve bu ilişkinin konu ve alanla bağlantılı dengesinin önemi düşünüldüğünde yukardaki görüş anlamlı olarak değerlendirilebilir.

Türkiye'de hemşirelik alanında yapılan araştırmaların yeterli nitelikte ve nicelikte olmadığı belirtilmektedir (Dağcı, 2019; Karabulut, Gürçayır ve Aktaş, 2019; Paşalak, Eroğlu ve Akyüz, 2018). Benzer şekilde, Kuzey Kıbrıs'ta da lisansüstü eğitim talepleri son on yıllık süreçte başlayıp artış göstermekle birlikte kadın sağlığına yönelik yapılmış tezlerin nitelik ve nicelik açısından yeterli olmadığı düşünülmektedir.

\section{Sonuç ve Öneriler}

Bu çalışma, Kuzey Kıbrıs’ta yer alan bir üniversitede kadın sağlı̆̆ ile ilgili yapılmış 21 hemşirelikte lisansüstü tez çalışmalarını belgesel kaynak analizi ve içerik analizi yöntemleriyle incelemek amacıyla yapılmıştır. Araştırma sonuçlarının, Kuzey Kıbrıs’ta kadın sağlığı ile ilgili yapılacak olan araştırmalara yol gösterici olacağı düşünülmektedir. Ayrıca, ülkede kadın sağlığı ile ilgili konulara ve hemşirelikte lisansüstü tezlerin içerik analizleri ile ilgili çalışmalara ilişkin literatüre katkı sağladığı düşünülmektedir. 
Kuzey Kıbrıs’ta Kadın Sağlığı ile İlgili Yapılmış Hemşirelikte Lisansüstü Tezlerin Özellikleri: Bir İçerik Analizi Çalışması

A Content Analysis Study: Characteristics of Postgraduate Dissertations in Nursing Concerning Women's Health in North Cyprus

- Araştırmada 'Kadın sağllğı ile ilgili hemşirelikte yapılmış lisansüstü tezlerin genel özellikleri (konu alanı, tez türü, örgüt türü) nelerdir?' sorusuna yanıt aranmış olup sonuç olarak; çalışma kapsamında ele alınan tez çalışmalarının daha çok yüksek lisans programında yürütüldüğü, çoğunlukla kadın sağlı̆̆ının geliştirilmesine yönelik konularda yapıldığı ve cinsellikle ilgili çalışmalara rastlanmadığı, doktora tezlerinde kuram/model kullanılmadığı, tezlerin çok azının yayına dönüştürüldüğü saptanmıştır. $\mathrm{Bu}$ sonuçlar doğrultusunda; Kuzey Kıbrıs'ta kadın sağlığının korunmasına, geliştirilmesine, iyileştirilmesine ve sürdürülmesine yönelik çok yönlü hemşirelik araştırmalarının artırılması, kadın sağlığı ile ilgili hemşirelikte yapılan doktora tezlerinde kuram/model kullanılması ve çalışmaların yayına dönüştürülmesi bakımından hemşirelerin desteklenmesi önerilmektedir.

- Araştırmada 'Kadın sağlığı ile ilgili hemşirelikte yapılmış lisansüstü tezlerin araştırma yöntem ve teknikleri nelerdir?' sorusuna yanıt aranmış olup sonuç olarak; çalışma kapsamından ele alınan tez çalışmalarında, ölçek kullanımın az olduğu, çalışmaların betimleyici/tanımlayıcı düzeyde olduğu, sadece bir deneysel çalışmanın yapıldığı, veri toplama tekniği ile örnekleme teknik türü bildirimi yapılmasında hata ve eksikliklerin olduğu, en fazla anket ile teke tek görüşme tekniğinin kullanıldığı bulunmuş̧tur. Bu sonuçlar doğrultusunda; hemşirelikte yapılan çalışmaların yöntem ve tekniğinde görülen eksikliklerin gelecekte yapılacak olan çalışmalarda dikkate alınması, deneysel araştırmaların ve çalışmalarda ölçek kullanımının yaygınlaştırılması, hemşirelik alanında bilimsel araştırma ve teknikleri konusunda verilen ders ve seminerlerle tez danışmanlık desteğinin niteliğinin artırılması önerilmektedir.

\section{Kaynakça}

Akalpler, Ö. ve Eroğlu, K. (2015). Kuzey Kıbrıs Türk Cumhuriyeti’nde üniversite öğrencilerinin sık görülen cinsel yolla bulaşan enfeksiyonlara ilişkin bilgileri ve cinsel davranışları. Hacettepe Üniversitesi Hemşirelik Fakültesi Dergisi, 2(2), 1-19. Erişim adresi: https://dergipark.org.tr/en/download/article-file/88660

Akalpler, O. ve Okumus, H. (2018). Gum chewing and bowel function after caesarean section under spinal anesthesia. Pakistan Journal of Medical Sciences, 34(5), 1242-1247. doi:10.12669/pjms.345.15772

Aksayan, S., Bahar, Z. ve Bayık, A. (2004). Hemşirelik disiplini ve araştırma. İ. Erefe (Ed.). Hemşirelikte Araştırma İlke Süreç ve Yöntemleri (3. bs.) (s. 13-26) içinde. Ankara: Hemşirelikte Araştırma ve Geliştirme Derneği.

Ardahan, M. ve Özsoy, S. (2015). Türkiye'de hemşirelik araştırmalarındaki eğilimler: Yüksek lisans ve doktora tezleri üzerine bir çalışma. Gümüşhane Üniversitesi Sağllk Bilimleri Dergisi, 4(4), 516534.

Asit, G. (2019). Kuzey Kıbrıs Türk Cumhuriyeti medyasında etik sorunsalı: Kürtaj davası haberleri örneği. Gümüşhane Üniversitesi İletişim Fakültesi Elektronik Dergisi, 7(1), 321-344. doi: 10.19145/e-gifder.424181

Best, J. (1959). Research in education. New Jersey: Prentice Hall.

Bogdan, R. C. ve Biklen, S. K. (1982). Qualitative research for education: An introduction to theory and medhods. Boston: Allyn and Bacon. 
Çakıcı, M., Çakıcı, E., Bayraktar, F., Subaşı, B., Karademir, D., Kayagül, F. ve Atabey, E. (2001). KKTC'de kadına yönelik şiddet. Kıbrıs Türk Tıp Dergisi, 2(2), 4-23.

Çakıcı, M., Düşünmez, S. ve Çakı1ı, E. (2007). Kuzey Kıbrıs'ta kadına yönelik şiddet. Lefkoşa: Kıbrıs Türk Ruh Sağlığı Derneği.

Dağc1, M. (2019). Türkiye'de 2008-2018 yılları arasında model ve kuram kullanılmış hemşirelik araştırmaları: Sistematik inceleme. İstanbul Gelişsim Üniversitesi Sağllk Bilimleri Dergisi, (9), 929-943. doi: 10.38079/igusabder.591038

Devlet Planlama Örgütü (DPÖ). (2017). Ekonomik ve sosyal göstergeler / istatistik yıllı̆̆g 2011-2015. Erişim adresi: http://www.devplan.org/frame-tr.html

Durmuş, H. A. (2016). Türkiye'de hemşirelikte nitel araştırmaların durumu. Ege Üniversitesi Hemşirelik Fakültesi Dergisi, 32(1), 90-96. Erişim adresi: https://dergipark.org.tr/en/pub/egehemsire/issue/49333/630123

Duverger, M. (1973). Sosyal bilimlere giriş: Metodoloji açısından (Ü. Oskay, Çev.). Ankara: Bilgi Yayınevi.

Emiroğlu, O. N., Kuru, N. ve Çopur, E. Ö. (2018). Türkiye'de 2009-2016 yı1ları arasında iş sağlığı hemşireliği alanında yürütülen lisansüstü tezlerin değerlendirmesi. Hacettepe Üniversitesi Hemşirelik Fakültesi Dergisi, 5(2), 116-127. Erişim adresi: https://www.researchgate.net/profile/Nilguen_Kuru_Alici/publication/332410644_

Hinçal, E., Taneri, B., Taneri, U. ve Djamgoz, M. B. (2008). Cancer incidence in North Cyprus (19902004) relative to Europe Anrates. Asian Pac J CancerPrev, 9(4), 725-732. Erişim adresi: http://journal.waocp.org/?sid=Entrez:PubMed\&id=pmid:19256767\&key=2008.9.4.725

Kaptanoğlu, A. F., Süer, K., Diktaş, H. ve Hinçal, E. (2013). Knowledge, attitudes and behaviour towards sexually transmitted diseases in Turkish Cypriot adolescents. Centeur J Public Health, 21(1), 54-58. doi:10.21101/cejph.a3808

Karabulut, N., Gürçayır, D. ve Aktaş, Y. Y. (2019). Hemşirelik araştırma tarihi. ACU Sağlık Bil Derg, 10(2), 121-128. doi: 10.31067/0.2018.48

Madge, J. (1965). The tools of science an analytical description of social scince techniques. New York: Anchor Books.

Mammadov, B., Vural, G., Aytac, E. ve Mammadov, E. (2019). Novel design of a three-dimensional printed umbilical cord clamp: A proof of concept study. Asme. J. Med. Devices, 13(3), 035002. doi: $10.1115 / 1.4043763$

Mammadov, B., Vural, G. ve Tosun, Ö. (2018). Risk factors associated with intimate partner violence during pregnancy in Northern Cyprus. Cyprus J Medsci, 1, 9-14. doi: 10.5152/cjms.2018.312

Masaroğulları, N. ve Uzunboylu, H. (2017). Kadına yönelik şiddet ve nedenleri. International Journal of Innovative Research in Education, 4(2), 85-96. doi: 10.18844/ijire.v4i2.2319

Mertan, B., Bayraktar, F., Pehlivan, G., Maner, U., Hüsnü, Ş. ve Çelik, D. (2012). Knowledge and attitudes toward domestic violence against women: The case of North Cyprus. Kadin/Women 2000, 13(2), 47-60.

NEU Grand Library. (2020). Library catalogue. Erişim adresi: http://library.neu.edu.tr/cgibin/koha/opac-main.pl

Özlüses, E. ve Çelebioglu, A. (2014). Educating fathers to improve breastfeeding rates and paternalinfant attachment. Indian Pediatrics, 51(8), 654-657. doi: 10.1007/s13312-014-0471-3

Paşalak, Ş. İ., Eroğlu, K. ve Akyüz, A. (2018). Kadın sağlığı hemşireliği alanında yapılan araştırmalarda kuram/model kullanımı. Ege Üniversitesi Hemşirelik Fakültesi Dergisi, 34(1), 91-108. Erişim adresi: https://dergipark.org.tr/en/pub/egehemsire/issue/36787/327105 
Kuzey Kıbrıs’ta Kadın Sağlığı ile İlgili Yapılmış Hemşirelikte Lisansüstü Tezlerin Özellikleri: Bir İçerik Analizi Çalışması

A Content Analysis Study: Characteristics of Postgraduate Dissertations in Nursing Concerning Women's Health in North Cyprus

Pervaiz, R., Tulay, P., Faisal, F. ve Serakinci, N. (2017). Incidence of cancer in the Turkish Republic of Northern Cyprus. Turkish Journal of Medical Sciences, 47(2), 523-530. doi: 10.3906/sag$1510-145$

Sancar, N., Nalca Andrieu, M., Hincal, E. ve Granit, D. (2017). Cancer incidence 2010-2014 among the North Cyprus population of adults aged 15 and over. Turkish Journal of Oncology / Türk Onkoloji Dergisi, 32(2), 43-54. doi: 10.5505/tjo.2017.1583

Sarpkaya, D. ve Eroğlu, K. (2011). Use of family planning methods among 15-49 age group women and affecting factors in Turkish Republic of Northern Cyprus. Turkiye Klinikleri Journal of Medical Sciences, 31(5), 1236-1244. doi: 10.5336/medsci.2011-22539

Sarpkaya Güder, D., Yalvaç, M. ve Vural, G. (2018). The effect of pregnancy Pilates-assisted childbirth preparation training on childbirth fear and neonatal outcomes: A quasi-experimental / quantitative research. Qual Quant, 52, 2667-2679. doi: 10.1007/s11135-018-0682-0

Sarpkaya Güder, D., Yalvaç, M. ve Vural. G. (2019). The effect of childbirth preparation training on primiparous women's birth plans and the childbirth processes. Clinical and Experimental Obstetrics \& Gynecology, 46(6), 924-932. doi: 10.12891/ceog4931.2019

Sökücü Yorgancı, F. ve Aslan, E. (2012). Kadının çalışma durumunun emzirmeye etkisi. İstanbul Üniversitesi Florence Nightingale Hemşirelik Dergisi, 20(1), 62-68.

Spear, H. J. (2007). Nursing theory and knowledge development: A descriptive review of doctoral dissertations, 2000-2004. Advances in Nursing Science, 30(1), 1-14.

Süer, H. K., Güvenir, M., Güler, E. ve Diktaş, H. (2012). Kuzey Kıbrıs Türk Cumhuriyeti Yakın Doğu Üniversitesi Hastanesi'ne başvuran kan donörlerinde HBsAg, Anti-HCV, Anti-HIV ve Sifilis test sonuçlarının değerlendirilmesi. Klimik Dergisi, 25(3), 99-102. doi: 10.5152/kd.2012.28

Şafak, Ç. ve Tutkun, N. A. (2015). Anne sütü ile beslenme sürelerinin yaşam çözümlemesi ile incelenmesi: Kuzey Kıbrıs Türk Cumhuriyeti örneği. İzmir Dr. Behçet Uz Çocuk Hastanesi Dergisi, 5(3), 167-176. doi: 10.5222/buchd.2015.167

Yalvaç, M. (2000). Kütüphane ve bilgi merkezlerinde sistem analizinin önemi ve uygulanabilirliği: Bir örnek: İstanbul Universitesi Kütüphane ve Dokümantasyon Daire Başkanlığl Bağll Birimlere Yayın Sağlama Alt Sistemi'nde sistem analizi uygulaması. İstanbul: Çantay Kitabevi.

Yüksel Koçak, D. ve Büyükkayacı Duman, N. (2019). Türkiye'de hemşirelik alanında üreme sağlı̆̆ıcinsel sağlık konularında yapılmış olan tezlerin içerik açısından incelenmesi. ACU Sağlık Bil Dergisi, 10(2), 265-270.

Yıldırım, A. ve Şimşek, H. (2006). Sosyal bilimlerde nitel araştırma yöntemleri (5. bs.). Ankara: Seçkin Yayincilik.

Yıldırım, B. (2015). İçerik çözümlemesi yönteminin tarihsel gelişimi uygulama alanları ve aşamaları. B. Yıldırım (Der.). İletişim Araştırmalarında Yöntemler: Uygulama ve Örneklerle (s. 105-155) içinde. Konya: Literatürk Akademia. 